\title{
Evacuation and Sheltering of Hospitals in Emergencies: A Review of International Experience
}

\author{
Dr. Jayshree Bagaria, MB ChB, MRCP, DTM\&H, MSc PH, MFPH; \\ Dr. Caroline Heggie, MB ChB, BSc Hons, MRCP; Jonathan Abrahams, BSc, MPH; \\ Professor Virginia Murray, FFOM, FRCP, FRCPath, FFPH
}

1. Specialist Registrar Public Health, Oxford Post Graduate Medical Deanery, seconded to Chemical Hazards and Poisons Division, Health Protection Agency, London

2. Emergency Medicine Trainee on secondment to Chemical Hazards and Poisons Division, Health Protection Agency, London

3. Coordinator, Risk Reduction \& Emergency Preparedness EPC/HAC WHO, Geneva

4. Consultant Medical Toxicologist, Chemical Hazards and Poisons Division, Health Protection Agency, London UK

Correspondence:

Professor Virginia Murray, FFOM, FRCP, FRCPath, FFPH

Consultant Medical Toxicologist

Chemical Hazards and Poisons Division, Health Protection Agency

7th floor Holborn Gate

330 High Holborn, London WC1V 7PP UK

E-mail: Virginia.Murray@hpa.org.uk

This is a document of the World Health Organization. Prehospital and Disaster Medicine was granted permission to use this work.

Keywords: chemical spill; disaster; evacuation; fire; flood; hospital; international

Web publication: 05 October 2009

\section{Abstract}

Objective: A scoping exercise to establish how common hospital evacuations are, identify hospital evacuation policies and review case studies to identify triggers, processes and challenges involved in the evacuation of hospitals globally. Design: A systematic search of PubMed and disaster agency online resources, search of grey literature and media reports.

Results: This study showed that hospitals are vulnerable to both natural and man made disasters and that hospital evacuations do occur globally. It highlighted the paucity of published data and policy on hospital evacuation and emphasised the vital need to collect data on triggers, reasons for evacuation, sheltering facilities and the process of evacuation.

Conclusions: This study recommends the collection of case studies and the development of a database to assist with the research and development of well tailored hospital evacuation plans. These recommendations reflect and support the 2008-2009 World Disaster Reduction Campaign on Hospitals Safe from Disasters and the timely 2009 Global Platform priority that, 'Critical services and infrastructure such as health facilities and schools must be safe from disasters.

Bagaria J, Heggie C, Abrahams J, Murray V: Evacuation and sheltering of hospitals in emergencies: A review of international experience. Prebosp Disaster Med 2009;24(5):461-467.

\section{Introduction}

Hospitals are powerful symbols of social progress with the World Disaster Reduction Campaign on Hospitals Safe from Disasters Campaign ${ }^{1}$ referring to them as 'a prerequisite for stability and economic development' having 'symbolic social and political values which contribute to a community's sense of security and wellbeing. ${ }^{2}$

However, hospital vulnerability varies throughout the world both in terms of location and events. For example, in Latin America and the Caribbean reports state that $50 \%$ of healthcare facilities (includes all health resources in a community such as hospitals, primary healthcare clinics) are located in highrisk areas. ${ }^{3}$ Indeed, even in developed countries such as the United Kingdom, $7 \%$ of hospitals and $9 \%$ of primary healthcare facilities are located on high or moderate risk flood areas. ${ }^{4}$ In terms of event five London hospitals have required partial or complete evacuation of inpatients, carergivers and visitors following fires during the last two years including a general hospital, a specialist cancer hospital, and a medium secure psychiatric unit.

Evacuation of a hospital is a complex process with the goal "to safeguard the health and lives of its occupants". "It was defined at the 2003 Pan American Health Organisation (PAHO) led conference Hospitals in Disasters: Handle with Care as the "organized withdrawal or removal (of persons or things) from a place or area, especially as a protective measure". 6

The implications of a hospital evacuation are much wider than the immediate functional loss of critical health services including emergency departments, intensive care units (ICU), operating theatres, as well as laboratories, blood banks, reha- 
bilitation facilities and/or pharmacies. They also create social and financial burdens spanning all sectors of society. This includes the direct financial implications from the loss of a health facility, indirect costs from decreased efficiency, loss of individual opportunities, income and productivity and damaged public moral and confidence in government. ${ }^{2}$

In view of this real and apparent risk, it has become increasingly evident that better information is needed globally on the evacuation and sheltering experience of hospitals. This report includes a scoping exercise of online literature, commissioned by the WHO. The objectives were to establish from the literature, the frequency hospital evacuations, identify hospital evacuation policies and review international case studies to identify triggers, processes, and challenges involved in the evacuation of hospitals.

\section{Methods}

The following approaches were used to search for information:

1. A systematic online literature search of PubMed, the Safe Hospital campaign website, PAHO, the Centre for Research on Disaster Epidemiology databases (CRED), and other allied organisations online documents. Evacuation guidance and case studies of hospital evacuation published after 1980 were identified. The terms 'hospital or healthcare facility', 'disaster or hazard' and 'evacuation or closure' were used in the search as free text and as $\mathrm{MeSH}$ terms using the Boolean operator 'AND' to combine the searches;

2. References from relevant documents were consulted;

3. Personal communications with relevant WHO staff counterparts;

4. Analysis of grey literature; and

5. Informal news media searching.

Any internal or external events such as disasters from natural events, chemical, biological, radiation, nuclear or explosive events (CBRNE) resulting in partial or complete hospital evacuations were included. Acts of war were excluded. Only hospital evacuation was included. Healthcare facilities such as nursing homes and other health facilities were excluded.

Case studies were selected following analysis of title and abstracts. Articles were reviewed using quantitative and qualitative analysis. Data were extracted on triggers, type and timing of evacuation, administration, and plans for evacuation, sheltering, effects on health and challenges.

\section{Results}

Results are divided into three sections: (1) establishing the scale of the problem; (2) a review of hospital evacuation events in the literature and media; and (3) an overview of policy and guidance available internationally on hospital evacuation.

\section{Establishing the Scale of the Problem}

Few published, peer-reviewed literature studies on the frequency of hospital evacuations internationally were found. Only two studies from the United States were identified in the published literature, which gave an indication of the frequency of hospital evacuation internationally:

Sternberg et al (2004) reviewed academic, newspaper, and US Fire Administration data on incidents involving hospital evacuation between 1971 and $1999 .{ }^{7}$ The study showed that there were 275 hospital evacuations during this period. More than half of the evacuations were due to hazards originating from within the hospital facility itself. Overall the study showed increasing numbers of hospital evacuations decade by decade with less than one evacuation per year in the $1970 \mathrm{~s}, 5.7$ per year in the $1980 \mathrm{~s}$ and 20.8 in the $1990 \mathrm{~s}$. The most common reason for evacuation during the study time period was an internal fire (23\%). Internal hazardous material (HazMat) incidents were the second most common reason for evacuation followed by hurricanes, human threat, and earthquakes. The second study by Burgess et al (1999) surveyed 101 hospitals in Washington State with emergency care facilities and found $12(13 \%)$ had evacuated in response to hazardous material incidents between 1991-1996. ${ }^{8}$ Further information on 11 of the incidents showed that seven occurred in emergency departments with inhalation being the most common hazard exposure route.

\section{Hospital Evacuation Events}

Most of this section consists of analysis of case studies published in the literature. However there also are large numbers of hospital evacuation events reported in the media and these have been discussed separately.

Case Study Data Extraction-Thirty-eight published cases studies obtainable within a six week time period from April to mid May, were shortlisted from the review of titles and abstracts. Twenty-one of these articles gave good case study descriptions of 69 hospitals, 30 of which reported having intensive care units. ${ }^{8-29}$ Of these, 17 articles document events from the US and four from Canada.

The breakdown of the case studies published in studies after 1980 , according to type of disaster, number of events and hospitals evacuated are in Table 1. Case studies were analysed to determine the triggers, type and timing of evacuation, administration and plans for evacuation, sheltering, effects on health, and challenges experienced during the evacuation process.

\section{Triggers for Evacuation}

In response to disasters related to natural events, 45 hospitals were evacuated. Of these, 29 were evacuated for two earthquakes and 15 for three hydro-meteorological events. Eight of these were evacuated in advance of hurricane landfall of which seven were to avoid the consequences of Hurricane Katrina. A combination of flooding and power failure caused evacuation of the remaining hospitals. Earthquakes causing non-structural damage, such as power failure, water damage from burst pipes, sprinklers and ruptured rooftop tanks, destruction of supplies, and failed ventilation systems resulted in the evacuation of at least 26 hospitals. Of the 24 hospital evacuations resulting from 21 human-made incidents, 11 were due to spills or contaminated patients. Other reasons for evacuation included power failure and a bomb threat.

\section{Type and Timing of Evacuation}

Twenty-eight evacuations were complete and 41 partial. The majority of hospitals affected by natural hazards or flooding 


\begin{tabular}{|l|l|c|c|}
\hline Category of Disaster & \multicolumn{1}{|c|}{ Nature of Disaster } & Number of Events & $\begin{array}{c}\text { Number of Hospitals } \\
\text { Evacuated }\end{array}$ \\
\hline \multirow{5}{*}{ Human-Made Incidents } & Nuclear power events & 1 & 4 \\
\cline { 2 - 4 } & Fire & 3 & 3 \\
\cline { 2 - 4 } & Chemical Events & 15 & 15 \\
\cline { 2 - 4 } & Other & 2 & 2 \\
\hline \multirow{5}{*}{ Natural Hazards } & Hydro-meteorological & 3 & 15 \\
\cline { 2 - 4 } & Earthquake & 2 & 29 \\
\cline { 2 - 4 } & Other & 1 & 1 \\
\hline Total & & 27 & 69 \\
\hline
\end{tabular}

Table 1-Number of events and hospitals evacuated by type of event (1979 to date)

\begin{tabular}{|c|c|c|c|c|c|}
\hline \multirow[t]{2}{*}{ Category of Disaster } & \multirow[t]{2}{*}{ Nature of Disaster } & \multicolumn{4}{|c|}{ Number of Hospitals Evacuated by Shelter Site } \\
\hline & & \multirow[t]{2}{*}{$\begin{array}{l}\text { Movement of } \\
\text { Patients within } \\
\text { Hospital }\end{array}$} & \multicolumn{2}{|c|}{$\begin{array}{l}\text { Planned Agreement for Transfer to } \\
\text { Unaffected Secondary Hospital }\end{array}$} & \multirow[t]{2}{*}{ Other or Unknown } \\
\hline \multirow{5}{*}{ Human-Made Events } & & & Yes & No & \\
\hline & Nuclear Power & & & 4 & \\
\hline & Fire & 1 & & 2 & \\
\hline & Chemical Events & 12 & 1 & 2 & 1 \\
\hline & Other & & 1 & 1 & 1 \\
\hline \multirow{3}{*}{ Natural Hazards } & Hydro-meteorological & & 8 & 3 & 4 \\
\hline & Earthquake & 16 & & 8 & 5 \\
\hline & Other & & & 1 & \\
\hline
\end{tabular}

Table 2-Number of hospitals evacuated by shelter site and type of disaster

were completely evacuated, whereas those affected by chemicals, internal fires, or nuclear events usually were partially evacuated. From cases in which the data were available, 48 evacuations immediately followed the event, and nine were delayed evacuations (up to 14 days). Three evacuations were planned, two to avoid the consequences of hurricane Katrina. Immediate evacuation for short periods of time ( $<24$ hours) was common in chemical events. Delayed evacuation tended to occur in natural hazards where non-structural damage had occurred or where access to buildings was limited following the event. Three hospitals never re-opened as a consequence of disasters due to natural hazards. The duration of evacuation was unknown in 35 cases.

\section{Administration and Evacuation Plans}

Forty-one hospitals managed their own evacuation process. Three described evacuation as part of a community wide operation. Generally, when hospitals managed their own evacuation process, emergency services command posts were set up to control the process. Following an earthquake, one hospital evacuated the healthiest patients first, ${ }^{11}$ but nine articles report moving critically ill patients first. Eight articles describe how patient notes were transported with patients. One hospital transferred notes electronically. ${ }^{30}$

Only four of the 69 hospitals report having a specific evacuation plan. Fifteen additional articles mentioned the presence of disaster plans, but these were not necessarily tailored to the evacuation of the facility. One of the papers describes flooding and power loss following a tropical storm affecting a newly built hospital that had been built according to 100 year flood standards. ${ }^{22}$

\section{Shelter}

Table 2 lists shelter sites used in different forms of disaster. When patients were moved to locations outside their primary hospital alternative hospitals were the most commonly used site. Chemical incidents causing short-term evacuation, often of an accident and emergency unit, tended to lead to 
internal evacuation. Other facilities used included unused areas of nursing homes and community colleges.

\section{Health Effects of Evacuation}

Three of the articles discussed the direct effects of hospital evacuation on patient morbidity and mortality. One article outlining evacuation of patients in the aftermath of Hurricane Katrina, highlighted two patients who lost their lives in the evacuation. The other two articles describing evacuation of a veteran centre outline the impact of evacuation on patient morbidity. This included delays in medication, delay in receipt of diagnostic procedures, duplication of procedures and alteration in mood, and emotional well-being.

\section{Challenges to Evacuation}

The two most commonly noted challenges were communication both internal and external, and logistics particularly concerning the movement of patients within and outside of the hospital.

Communication was noted as a challenge in 14 of the 21 articles. Congestion of telephone circuits, failure of emergency equipment, and difficulties communicating with other agencies such as fire and police were mentioned. A central command post or a pre-arranged transfer agreement with shelter sites facilitated the search for appropriate shelter sites.

Logistic challenges included management of patient transfers both internally and externally. Particular challenges experienced during the internal movement of patients included non-functioning elevators, compromised access to stairwells or evacuation routes, and failed lighting and electrical circuits, often as a consequence of flooded basements holding electric circuits. Decisions and challenges accessing appropriate modes of transport used in transferring patients from one hospital site to an alternative site often were complicated, particularly where multiple evacuations were occurring simultaneously.

Media-Based Reports-Despite the paucity of published literature on hospital evacuation, reports were not uncommon in the online news media. Examples include bushfires in 2001 causing the evacuation of two hospitals in New South Wales, Australia, ${ }^{31}$ numerous news reports highlighting incidents of hospital evacuation in the aftermath of tropical storm Allison (2001) and Hurricane Katrina (2005), 32,33 and a suspected paraquat poisoning apparently causing evacuation of parts of Tauranga Hospital, New Zealand. ${ }^{34}$ Another report related to preparedness in 2004 when military tents were set up in Indonesia following an earthquake, to treat the injured outside of a hospital in case it collapsed. ${ }^{35}$

More recent examples of evacuation include the five London hospitals evacuated for fire in 2008-2009, closure of the Accident \& Emergency Department at the Mater Misericordiae Hospital in Dublin due to flooding in 2009, evacuation of L'Aquila in Italy Hospital in the aftermath of the 2009 earthquake, and the evacuation in 2009 of a newly built and operational hospital in Sicily due to concerns that it would not withstand an earthquake. ${ }^{36-43}$

The media reports mentioned have focused on hospital evacuation but there also are numerous cases in which hospitals have collapsed with little information on survivor outcomes. At least 42 hospitals in India and Sri Lanka were destroyed following the 2004 South East Asian tsunami, the Shifang Women and Children's Hospital was destroyed following the 2008 earthquake in China, and parts of Rangoon Hospital, Burma were ruined following cyclone Nargis in 2008. ${ }^{44-46}$

\section{Policy}

A search of published policy on the need for hospitals to prepare for evacuation can be divided into three main groups: (1) international policy; (2) national policy; and (3) local or organisational policy.

International-The Hyogo Framework for Action for 2005-2015, (priority 4: reduce underlying factors) recommends the integration of disaster risk reduction planning into the health sector; promoting the goal of "hospitals safe from disasters". ${ }^{47}$ This priority framed the development of the 2008-2009 World Disaster Reduction Campaign Hospitals Safe from Disasters: Reduce Risk, Protect Health Facilities, Save Lives, jointly organized by the WHO, UNISDR, and World Bank.,2 The primary aim of this campaign is to create hospitals that are safe and able to function during and after a disaster-causing event. This concept was once again highlighted at the as the theme of World Health Day 2009 and 2009 Global Platform for Disaster Risk Reduction that emphasized that "making hospital and health facilities safe from disaster is a health imperative and an economic requirement, as well as a social and ethical necessity". 48

A critical element of hospital evacuation planning and training are the risk assessment skills of staff in deciding whether or not evacuation is necessary. The 2001 PAHO Disasters newsletter discussed this issue emphasising that need for evacuation should be based on four aspects: (1) whether the magnitude of physical damage make evacuation necessary; (2) whether the entire facility should be evacuated; (3) how provision of continuing healthcare can be guaranteed for the population; and (4) to where the facility should be evacuated. This article and the 2003 Hospitals in Disasters: Handle with Care Conference also highlight the financial and social burden of inappropriate evacuations that often are triggered by inaccurate perceptions of risk. ${ }^{5,6}$

The Hospital Safety Index developed by PAHO's Disaster Mitigation Advisory Group advises healthcare facilities how to assess their safety including the need for emergency operations plans and procedures for evacuation in response to internal and external disasters. ${ }^{3}$

National-An example of the development of a national policy is that of the UK. The Cabinet Office issued Guidance on Evacuation and Sheltering in $2006 .{ }^{49}$ They recommended that National Health Service (NHS) Trusts should have procedures for evacuating taking into account the overall risk to patients, appropriate safe transport and patient-tracking mechanisms, and have a planned appropriate destination. In April 2009 the Department of Health published their interim strategic guidance, Planning for the Evacuation and Sheltering of People in Health Sector Settings. ${ }^{50}$ This further provides best-practice guidance for 
the NHS in England to plan, prepare and manage evacuation and sheltering of people from healthcare settings. This further provides best-practice guidance for the NHS in England to plan, prepare and manage evacuation and sheltering of people from health care settings whilst also providing a framework for health service managers to design and plan a coordinated response. It also provides preparatory training for staff involved in response. The policy further focuses on exercising emphasising that this should occur in the planning phase and be a formal part of an organisation's staff training and education. It states that exercises to support the requirements of the site and the likely risks faced should be undertaken. The guidance outlines that the NHS is required to undertake a "live" exercise every three years, a "tabletop" exercise every year and a test of communications cascades every six months. ${ }^{50}$

In the US, the National Response Plan (NRP) outlines how the Federal government will assist states and localities managing incidents and includes the National Disaster Medical System (NDMS), a program that can assist state and local government to evacuate patients who need hospital care. These plans are reflected at the state and local levels. In addition, at the federal level, the Department of Health and Human Services (HHS) Centers for Medicare and Medicaid Services (CMS) require all participating hospitals to have plans to meet all potential emergencies and disasters although transfer of patients is not mentioned specifically. ${ }^{51}$

Local or Organizational-At an organizational or state level, hospitals in the US are further assessed by accrediting organisations such as the Joint Commission on Accreditation of Healthcare Organisations, the American Osteopathic Association, and state agencies. The Joint Commission Standards requires that accredited hospitals' emergency operations plans identify facility capabilities and establish response efforts including staged evacuation, and total evacuation including the transportation of patients, supplies, staff, and equipment to alternative care sites. At state level, Florida requires all of its hospitals to have emergency management plans, including transportation arrangements to be used when evacuating patients. ${ }^{51}$ An additional resource includes the New York Center for Bioterrorism Preparedness and Planning developed an evacuation planning toolkit for hospitals in 2006, in response to the experiences shared from the hospitals in New Orleans that were victims of Hurricane Katrina. ${ }^{52}$

\section{Discussion}

The 2009 Global Platform for Disaster Risk Reduction states that, "Critical services and infrastructure such as health facilities and schools must be safe from disasters' by 2015 and that the, "principle approach must consider structural and nonstructural elements of schools and hospitals, as well as emergency preparedness, including issues such as evacuation and sheltering and health and safety of teachers, children, health workers and patients". ${ }^{48}$

The paucity of published, peer-reviewed data available on hospital evacuations internationally is striking with an extreme disparity between the 65 USA hospital evacuation case studies identified herein (16 of which were after 2000) and Sternberg's paper outlining 275 hospital evacuations between 1971 and 1999 in the US (6 before 1980). In addition, widespread international policy tailored towards hospital evacuation is difficult to find highlighting an important gap in hospital disaster planning. It must be noted that the searches only sought articles and policies that were written in English.

Hospital evacuations do occur and hospitals are vulnerable to both internal and external hazards. These data demonstrate that chemical events, such as internal hospital spills, contaminated patients, or internal fires, are the most common incidents responsible for either partial or complete hospital evacuation, a finding corroborated by Sternberg and colleagues. ${ }^{7}$ But events due to natural hazards such as earthquakes or hurricanes cause the most significant evacuations of large numbers of hospitals during an individual incident.

From the data on hospital evacuation events, it has been shown that more information is needed on the decision processes employed when deciding whether or not to evacuate. ${ }^{5}$ The role of hazard risk perception in deciding whether or not to evacuate was emphasized at the 2003 Hospitals in Disasters: Handle with Care Conference. ${ }^{6}$

Aguirre et al comment that "the invocation of disaster plans and the increase in the level of response associated with disasters in the hospitals are a function of the hospitals staff's perception of the actual and/ or potential impact of hazards" ${ }^{53}$ This issue is highlighted by the two evacuations in advance of Hurricane Rita in an effort to avoid the consequences of Hurricane Katrina, ${ }^{17,30}$ and is particularly critical when the potential health implications of evacuation are considered, as has been shown by the increased mortality following hurricane Katrina and the increase in morbidity following evacuation of a veterans hospital. ${ }^{18,21,24}$

From this review, the absence of whole hospital evacuation in generic disaster plans is evident. The need for plans that tackle communication and consider transportation of patients is highlighted not only by the challenges outlined in the analysed case studies described but also by the report of the US Government Accountability Office on Limitations in Federal Evacuation Assistance for Health Facilities. ${ }^{51}$ Appropriate planning and training not only would help facilitate the evacuation process but would also help avoid unnecessary evacuation. Another recommendation includes the provision of comprehensive regular training and simulation exercises to all staff who may be involved in an evacuation. Such training and simulation not only allow staff to become skilled when enacting the plan but also help identify which challenges might be encountered when using the plan. The results of these exercises must feed into hospital evacuation plans.

In view of the results from this scoping exercise, the development of a tool to collect and evaluate data on hospital evacuation is recommended. This should feed into an international database held at a central location allowing public access for analysis. An example of such a tool would be that of Heggie and colleagues' adaptation of Schultz's benchmarking tool used in response to four of the UK London hospital fires. . $^{5,55}$

Further recommendations include the need for additional research on evacuation in different types of health- 
care facilities, including specialist facilities such as dialysis units, pediatric and elderly care units, pharmacies and other healthcare facilities such as primary care centres and nursing homes. In addition, further analyses into the process of evacuation with a focus on decision making processes and the health, social and financial impacts of evacuation are needed.

These recommendations are in line with the Hyogo Framework for Action, and would support national Safe Hospitals programmes supported by the WHO and its partners. One of the key aspects of the programme is to ensure a culture of disaster risk reduction is employed whilst building and adapting healthcare facilities. However, during an emergency or disaster, evacuation of a hospital or healthcare facility may be necessary despite appropriately intensive planning. ${ }^{22}$ In order to strengthen the safe hospital programs, a "memory" of evacuations from which lessons can be learned must be built to provide us with better information on evacuations as and when they occur. This would be in line with the ISDR Scientific and Technical Committee report on the Global Platform for Disaster Risk Reduction, which emphasized the need to integrate science and technology into policy. ${ }^{56}$ Such action

References

1. International Strategy for Disaster Risk Reduction (ISDR): Hospitals Safe from Disasters 2008-2009 World Disaster Reduction Campaign Available at http://www.unisdr.org/eng/public_aware/world_camp/2008-2009/wdrc2008-2009.html. Accessed April 2009.

2. WHO, PAHO, ISDR, World Bank: Hospitals safe from disasters: Reduce Risk, Protect Health Facilities, Save Lives. 2008. 2008-2009 World Disaster Reduction Campaign. (Report) Available at http://www.safehospitals.info/ or http://safehospitals.info/images/stories/1WhySafeHosp/wdrc-20082009-information-kit.pdf. Accessed April 2009.

3. WHO, PAHO, ISDR, World Bank: What is the hospital safety index? 2009. Available at http://safehospitals.info/index.php?option=com_content\&uask=view \&id=30\&Itemid=103 Accessed April 2009.

4. Environment Agency: Investing for the future flood and coastal risk management in England. A long term investment strategy. 2009. Bristol. (Report), Available at http://www.environment-agency.gov.uk/research/library/publications/108673.aspx. Accessed April 2009.

5. PAHO: Do we evacuate our hospitals prematurely? Disasters: Preparedness and Mitigation (85). 2001. Available at http $/ /$ www.paho.org/Project.asp?SEL=TP\& LNG=ENG\&JD=85\&PRGRP=periodicals. Accessed August 2009.

6. PAHO: Should a hospital be evacuated? Hospitals in disaster: Handle with Care Conference. San Salvador 8-10 July 2003. Available at http://www.disaster-info.net/hospital_disaster/background.htm. Accessed April 2009

7. Sternberg E, Lee GC, Huard D: Counting crises: US hospital evacuations, 1971-1999. Prehosp Disaster Med 2004;19:150-157.

8. Burgess JL: Hospital evacuations due to hazardous materials incidents. $A m J$ Emerg Med 1999;17:50-52.

9. Chavez $\mathrm{CW}$, Binder B: A hospital as victim and responder: the Sepulveda VA Medical Center and the Northridge earthquake. $J$ Emerg Med 1996;14:445-454.

10. Martchenke J, Pointer JE: Hospital disaster operations during the 1989 Loma Prieta earthquake. Prehosp Disaster Med 1994;9:146-153

11. Schultz $\mathrm{CH}$, Koenig KL, Lewis RJ: Implications of hospital evacuation after the Northridge, California, earthquake. N Engl J Med 2003;348:1349-1355.

12. Blumhagen DW: Evacuation of patients during a fire at a general hospital. Ann Emerg Med 1987;16:209-214.

13. Hogan C: Responding to a fire at a pediatric hospital. $A O R N$ 2002; 75:793-800.

14. Bernard M, Mathews PR: Evacuation of a maternal-newborn area during Hurricane Katrina. MCN Am J Matern Cbild Nurs 2008;33:213-23.

15. Gray BH, Hebert K. Hospitals in Hurricane Katrina: Challenges facing custodial institutions in a disaster. I Health Care Poor Underserved 2007;18:283-298. not only would allow facilitation of the actual evacuation process, e.g., through improved building regulation and communication means, but also would allow identification of changes that hospitals could make, in order to improve the efficiency of the evacuation process whilst also decreasing the number of evacuations in the future.

\section{Conclusions}

Hospitals are vulnerable to natural and human-made hazards and evacuations do occur globally. The absence of data on evacuated hospitals, as well as the lack of significant policy-driven plans locally, regionally, nationally, and internationally has been highlighted. A vital need to collect data on triggers, reasons for evacuation, sheltering facilities, and the process of evacuation has been identified. A centrally held database should be developed to assist with the research and development of well-tailored hospital evacuation plans and case studies. These recommendations reflect and support the 2008-2009 World Disaster Reduction Campaign on Hospitals Safe from Disasters and the timely 2009 Global Platform priority that, "Critical services and infrastructure such as health facilities and schools must be safe from disasters". 48

16. Norcross ED, Elliott BM, Adams DB, Crawford FA: Impact of a major hurricane on surgical services in a university hospital. Am Surg 1993;59:28-33.

17. Sexton KH, Alperin LM, Stobo JD: Lessons from Hurricane Rita: the University of Texas Medical Branch Hospital's evacuation. Acad Med 2007:82:792-796

18. Taylor IL: Hurricane Katrina's impact on Tulane's teaching hospitals. Trans Am Clin Climatol Assoc 2007;118:69-78.

19. Thomas J, Lackey N: How to evacuate a psychiatric hospital: a Hurricane Katrina success story. J Psychosoc Nurs Ment Health Serv 2008;46:35-40.

20. Augustine J, Schoettmer J: Evacuation of a rural community hospital: lessons learned from an unplanned event. Disaster Manag Response 2005;3:68-72.

21. Blaser MJ, Ellison RT 3rd: Rapid night time evacuation of a veterans hospital. J Emerg Med 1985;3:387-394.

22. Cocanour CS, Allen SJ, Mazabob J, Sparks JW, Fischer CP, Romans J, et al: Lessons learned from the evacuation of an urban teaching hospital. Arcb Surg 2002;137:1141-1145.

23. Cybulski P: Evacuation of a critical care unit. Dynamics 2003;14:21-23.

24. Fisher HL: Emergency evacuation of the Denver Veteran's Administration Medical Center. Mil Med 1986;151:154-161.

25. Henderson J, Gamble D: Evacuation. Nurs BC 1998;30:18-20.

26. Henry S: Mississauga Hospital: largest evacuation in Canada's history. $C M A$ Journal 1980;122:582-586.

27. Vasudevan $P$, Wade K: Total facility evacuation at Helena Regional Medical Center. J Ark Med Soc 1997;94:76-77.

28. Maxwell C: Hospital organizational response to the nuclear accident at Three Mile Island: implications for future-oriented disaster planning. $\mathrm{Am} \mathrm{J}$ Public Health 1982;72:275-279.

29. MacLeod JA, Blazey M, Johnson F, MacMullen JA: It's not a drill, it's for real! J Nurs Staff Dev 1994;10:293-299.

30. Gallagher JJ, Jaco M, Marvin J, Herndon DN: Can burn centers evacuate in response to disasters? J Burn Care Res 2006;27:596-599.

31. Bushfires force evacuation of two hospitals in western NSW. Available at http://www.abc.net.au/news/newsitems/200112/s445532.htm. Accessed 06 August 2009

32. Abelson R, Feuer A: 10,000 Patients and Staff Members Await Evacuation From Barely Functional Hospitals. Available at http:/www.nytimes.com/2005/09/01/ national/nationalspecial/01hospital.html. Accessed 06 August 2009

33. Cooper A, Koch K, Mattingley D: New Orleans shelters to be evacuated Available at www.cnn.com $/ 2005 /$ WEATHER/08/30/katrina/index.html. Accessed 06 August 2009.

34. Poison sparks evacuation at hospital. Available at http://tunz.co.nz/view/news national_story_skin/703375. Accessed 06 August 2009. 
35. AFP: One dead, dozens hurt in Indonesian earthquakes. Available at http://www.asiaone.com/News/Latest+News/Asia/Story/A1Story20090105112267.html. Accessed on 06 August 2009.

36. Mater Hospital A\&E closed. Availabe at http://www.irishtimes.com/newspaper/breaking/2009/0702/breaking15.htm. Accessed 06 August 2009.

37. Hooper J, Kington T, Addley E: Italy earthquake leaves 150 dead and scores more trapped under rubble. Available http:/www.guardian.co.uk/world/2009/apr/06/ italy-earthquake-victims. Accessed 06 August 2009

38. West D: London hospital fire: 250 evacuated. Available at http $/ /$ www.hsj.co.uk london-hospital-fire-250-evacuated/1988985.article Accessed 06 August 2009.

39. Firemen Wounded At Hospital Blaze. Available at http://news.sky.com/skynews/ Home/UK-News/Fire-At-Great-Ormond-Street-Hospital-For-Children-MassEvacuation/Article/200809415109087. Accessed 06 August 2009.

40. Fire forces hospital's evacuation. Available at http://news.bbc.co.uk $/ 1 / \mathrm{hi} / \mathrm{eng}$ land/london/7168206.stm. Accessed 06 August 2009.

41. Staines R: Patients evacuated following mental health unit fire. Available at http://www.nursingtimes.net/whats-new-in-nursing/patients-evacuated-following-mental-health-unit-fire/1898709.article. Accessed 06 August 2009.

42. Savage M: Great Ormond Street evacuated after fire. Available at http://www.independent.co.uk/news/uk/home-news/great-ormond-streetevacuated-after-fire-946105.html. Accessed 06 August 2009.

43. Willey D: Sicilian hospital 'a quake risk'. Available at http://news.bbc.co.uk/1/hi/ world/europe/8173680.stm. Accessed 06 August 2009.

44. WHO, SEARO: Counting the losses. Available at http//www.searo.who.int worldhealthday2009/focus/Counting_losses.htm. Accessed 06 August 2009.

45. Zhiling $\mathrm{H}$ : Buddhist temple acts as emergency maternity unit. Available at http://www.chinadaily.com.cn/china/2008-07/04/content_6819089.htm. Accessed 06 August 2009.

46. Survivors of cyclone left with nothing. Available at http://www.theaustralian.news.com.au/story/0,25197,23652207-25837,00.html. Accessed 06 August 2009.

47. UNISDR: Hyogo Framework for Action 2005-2015. Available at http://www.unisdr.org/eng/hfa/hfa.htm. Accessed 20 April 2009.
48. High Level Plenary Panel 4 "Safer Schools and Hospitals". Available at http:/www.preventionweb.net/globalplatform/2009/programme/plenary/v.p hp?id=110. Accessed 06 August 2009

49. The Cabinet Office. Evacuation and Shelter Guidance: Non-statutory guidance to complement Emergency Preparedness and Emergency Response \& Recovery. Available at http://www.cabinetoffice.gov.uk/media/132739/evac_shelter_guidance.pdf. Accessed 23 July 2009.

50. DH Emergency Preparedness Division: NHS Emergency Planning Guidance 2009 Planning for the evacuation and sheltering of people in health sector settings: Interim strategic national guidance. Available at http:/www.dh.gov.uk/en/ Managingyourorganisation/Emergencyplanning/DH_470. Accessed 31 May 2009.

51. Government Accountability Office: Disaster preparedness limitations in federal evacuation assistance for health facilities should be addressed. Available at http://www.gao.gov/cgi-bin/getrpt?GAO-06-826. Accessed 23 July 2009.

52. Centre for Bioterrorism Preparedness and Planning: Evacuation Planning for Hospitals draft document. Bioterrorism Hospital Preparedness Program. Available at http:/www.nyc.gov/html/doh/downloads/pdf/bhpp/bhpp-hospital-evac-plan.pdf. Accessed 23 July 2009.

53. Aguirre B, Dynes R, Kendra J, Connell R: Institutional Resilience and Disaster Planning for New Hazards: Insights from Hospitals. Journal of Homeland Security and Emergency Management 2005;2:1-17.

54. Heggie C, Bagaria J, Murray V, Philpott C: UK Hospital Evacuations: Building a Database of Lessons Learned. Global Platform for Disaster Risk Reduction. 18-6-2009. (Poster)

55. Schultz CH, Koenig KL, Auf der Heide E, Olson R: Benchmarking for hospital evacuation: a critical data collection tool. Prehosp Disaster Med 2005;20:331-342

56. ISDR Scientific and Technical Committee: Reducing disaster risks through science, issues and actions. Available at http:/www.preventionweb.net/globalplatform $/ 2009 /$ background/documents/SD-03-ENG-ScientificTechnical-Committee.pdf. Accessed 01 August 2009. 